\title{
DISKUSSIE
}

\section{IS DIE „OUDERLINGAMP” IN HAND. 6 INGESTEL?}

\section{B. Spoelstra skryf:}

In die vorige uitgawe (jrg. 10, nr. 37) opper kollega Floor interessante menings en beskouinge oor die Presbiter by Lukas en Paulus. Die kort artikel openbaar wye belesenheid en kennis van veral Duitse skrywers soos Käseman, Schweizer, Von Campenhausen en Goppelt. Op hulle voetspoor waag hy hom tot ' $n$ stelling dat ons in Hand. 6 ,die instelling van die ouderlingamp kry".

Ek het al so gewens dat dit kon waar wees! Indien dit so was, was ons dadelik van die problematiek rondom die diakenamp af, want dan was daar slegs apostels en ouderlinge wat ook opsieners genoem is om mee rekening te hou - en hierdie ouderlinge het gaandeweg gespesialiseer in regeer- en leer-ouderlinge (predikante). Eersgenoemde ouderlinge kon dan sommer ook vandag diakenwerk doen - en laasgenoemdes kon dan in Fil. 1 : 1 diakens (d.w.s. dienaars) genoem gewees het. Kortom, as Floor gelyk het, kan die regeerouderlinge sommer ons huidige diakens wees, terwyl ons huidige predikante sommer net ,diakens" genoem word. Die hele beskouing is eenvoudiger, makliker en ruim 'n hoop probleme op, hoewel daar iets kontradiktories op grond van Fil. 1 : 1 tussen ouderling en predikant in die lug bly hang.

1. Die verklaring is egter nie so eenvoudig nie. Voordat ons op suggestie van prof. Floor die afsonderlike diens van diaken in Hand. 6 opruim, geld van meet af twee probleme:

1.1. Die artikel van Floor gaan uiteraard mank aan eensydig. heid in sy opset. Hy wil kort gaan om by sy stelling te kom en haal outoriteite aan wat 'n basis vir sy stelling bied. Die getuienis van so baie eksegete wat tradisioneel wel die instelling van 'n diakendiens teenoor die opsienersdiens in Hand. 6 aangedui het, word verswyg en nie teen die Duitse outeurs geweeg nie. Dit is gevaarlik. Ek vind dit veral jammer omdat die gesprek by ons al tot op sinodes gevorder het (vgl. Acta 1964, bl. 392 e.v.; Acta 1970, bl. 338 e.v.).

1.2. Floor aanvaar geen teenstelling tussen periodes van 'n Ou- of charismatiese kerkinrigting by Paulus en geinstitusionaliseerde „Frühkatolizismus” by Lukas nie. Dit waardeer ek, want dit is onlogies dat die Ou Christelike Kerk so spoedig al in dubbelstrukture en teenstellings sou vasgeval het. Maar ewe so moet ons dan met die getuienis van die geskiedenis rekening hou. Die opeenvolgende jare beeld immers die verstaan van die oudste kerke gedurende die eerste eeue uit en daar was nooit 'n organisatoriese kloof tussen gemeentes uit die Jodendom, Grieke of Romeine nie. Inteendeel. Hulle mag verkeerd verstaan het - maar dan moet ons dit kan bewys. Ons kan hulle nie met veronderstellings of moontlikhede van die tafel reël nie.

In 'n artikel Geskiedenis van die diakenamp tot voor die refor- 
masie (In die Skriflig, jrg. 3, nr. 9) het ek aan hierdie historiese verstaan aandag gegee en bevind dat die Joodse tradisie ook 'n voorbeeld van nog 'n diens naas die ouderling gehad het (jongeres naas die oudstes); dat die idee van 'n kollege van sewe diakens hardnekkig bestaan het sodat selfs in 'n Romeinse stad (Rome) aan die getal sewe vasgeklem is tot in die sewende eeu; dat hierdie diens in die oudste bronne as 'n bepaalde en afsonderlike stoflike hulpdiens onder sorg van die biskop (opsiener) onderskei is; dat in die vierde eeu die aartsdiaken (deken) uit die diakens langs die biskop uit die opsieners (meervoud) uitgestyg het. Hierdie parallisme van diakens en opsieners kon tog nie sommer so vanself uniforme patroon in die hetrogene en betreklik losstaande gemeentes geword het nie, veral as selfs Rome aan die getal van sewe bly kleef het toe dit al in veertien wyke verdeel was nie. Dit dui tog op doelbewuste repristinasie van Hand. 6.

Daarby is daar uit Hand. 6 duidelike paralellisme aan te wys in verband met 'n diens van stoflike versorging deur diakens (in Jerusalem en daarna in die gemeentes van Klein Asië en Rome) en daarnaas die geestelike regering en opsig deur die apostels wat later deur die ouderlinge as opsieners beoefen word. Hierdie feite laat hulle dan tog nie sonder meer verklaar deur 'n stelling dat die ouderlingdiens in Hand. 6 ingestel is nie.

2. Hand. 6 word deur die verklaring van Floor nie duidelik nie. In Hand. 6 word die parallelle tussen die diens wat daar ingestel word en die diens van die apostels duidelik in Hand. $6: 2$ gegee. Daar word 'n diens om die Woord van God te bedien teenoor 'n diens om die tafels te bedien onderskei. Weliswaar meen Floor dat Hand. 11 : 30 daarop dui dat die „ouderlinge” die versorging van die broeders in Judea $(11: 29)$ onderneem het en die broeders van Hand. 6 derhalwe aandui. Daarteenoor staan egter in dieselfde boek Hand. 20 : 28 die taak van die ouderlinge duidelik as geestelike versorging van die kudde met die Woord en Gees teen die wolwe aangedui. Die geestelike diens as eintlike taak kom dan op presies dieselfde taak neer as wat die apostels in Jerusalem langs die bedienaars van die tafels volgens Hand. $6: 2$ vir hulleself reserveer het. Die onderskeiding tussen tafel (tydelike) en geestelike sorg word geaksentueer met die vereiste-spieël van 1 Tim. 3. Die eise vir die opsieners het met regeer te doen (vs. 1-7) terwyl die „diakens" afsonderlik gespieël word teenoor eise wat m.b.t. eerlikheid, integriteit en geen vuilgewinsoekers nie, d.w.s. dinge wat by die hantering van geld en stoflike dinge belangrik is.

3. Verskyn die begrip ,ouderling" onverwags in die N.T. indien hulle nie in Hand. 6 bedoel word nie? Floor wil die ouderlingamp aan Hand. 6 verbind omdat ons anders nergens lees van die instelling van die ouderlingamp nie. Hulle verskyn „onverwags" soos 'n „komeet" in die boek Handelinge (p. 25).

$\mathrm{Ek}$ is baie bang om uit hierdie feit enige afleiding te maak. 'n Konklusie kan immers nie op 'n argumentum e silentio rus nie, veral nie so 'n ingrypende gevolgtrekking nie. Waar lees ons van die ,ampte" waarvan ons in 1 Kor. 12 lees? Dink ons Westerlinge 
nie te struktureel oor „amp” en ,instelling” nie? Omdat die ouderlinge formeel bekend was uit die sinagoge, ag ek nie 'n formele bekendstelling van ouderlinge in die NT nodig nie - wat wel nodig was, is dat die N.T. duidelik die materiële inhoud van die diens of werk van die ouderlinge sou aandui en omskrywe en dit gebeur in Hand. $6: 2$ en $20: 28$.

Floor se hipotese dat Hand. 6 die instelling van ouderlinge verhaal, verklaar verder ook nog nie waarom die apostel Johannes hom in die derde brief „ouderling" noem nie (vs. 1). Daar is dus grond om aan te neem (soos talle doen) dat die apostolaat aanvanklik in Jerusalem die regering en so die „ouderlinge" verteenwoordig het en dat ander ouderlinge gaandeweeg bygekom en plaasvervangend die ouderlingskap van die apostels oorgeneem het. Hand. $14: 23$ en $20: 28,31$ bewys duidelik hoe ouderlinge juis opvolgers vir die apostels geword het. In die lig hiervan kan die woord ,ouderlinge" in Hand. 11 : 30 (waar hulle soos 'n komeet sou verskyn) net so goed op die apostels in die algemeen saam met of sonder ander bevestigde ouderlinge as die voorstanders van die gemeente dui. Die woord „ouderling" is immers nie die wesenlike naam vir die bepaalde diens nie. Die woord opsiener is meer beskrywend en eintlike term om die bepaalde diens aan te dui. Miskien kan ons dus sê dat „ouderling” meer formeel en „opsiener" meer inhoudelik dieselfde diens beskryf. Die apostels was immers ook opsieners en het juis in Hand. $6: 2$ vir hulle die diens van opsig gereserveer; hulle was op daardie stadium die ouderlinge in Jerusalem en derhalwe is dit nie nodig om die instelling van ouderlinge te vermeld nie.

Die diens van die tafels (Hand. 2 tot 6 ) is egter iets totaal nuut en besonder Nieu-Testamenties wat selfs in die O.T. geen voorbeeld gehad het nie. Derhalwe word die instelling van hierdic nuwe diakonia in Hand. 6 behoorlik aangedui - iets wat m.b.t. die ouderlingdiens nie nodig was nie. Ek verwys weer na Hand. 14: 23. Daar word die instelling van ouderlinge vermeld wanneer die apostels (wat tot nog toe die opsieners was) na die volgende stad vertrek.

4. Die gevaar van 'n retro-jeksie vanuit latere strukture moet voorkom word. By die lees van die artikel van Floor kon ek nie die indruk ontkom dat hier gevaar bestaan dat daar uitgegaan word van 'n aksioma oor ,amp”, ,diaken" en „,presbiteriaat" soos wat ons dit in latere jare leer ken het nie en dat die N.T. dan getoets word aan hierdie strukture en in die lig daarvan verklaar word nie. Een van die treffendste voorbeelde van hierdie soort retrojeksie vind ons m.i. in die bevestigingsformulier vir diakens. In Hand. 6 lees ons van manne wat vir bediening van die tafels gekies is. In latere jare is aanvaar dat die diakens die armes versorg het. Die Bevestigingsformulier het derhalwe geen probleem om met verwysing na Hand. 6 sommer net so tafels met armes te verwissel nie. Latere inkleding word sodoende teruggewerp op die eerste instelling.

4.1. In Floor se artikel het ek moeilikheid ondervind om uit te maak wat hy met die woord ,amp" bedoel. Die woord ken ek nie uit die N.T. nie, maar wel uit latere kerkregtelike besinning. Hy praat byvoorbeeld van die ,amp" langs en teenoor die „charisma" asof amp charisma kon verdring (p. 23); asof dit soos water en vuur 
vergelykbaar is (p. 24); teenstelling charisma en amp (p. 24); in Hand. 6 die ,instelling van 'n amp" (p. 25); 'n „ongedifferensieerde amp" (p. 26); die ,koördinaat charisma en amp" (p. 27) wat mekaar aanvul; die dubbelfunksie ,amp en gawe" (p. 27); gemeentes het nog die amp van ouderling geken nie (p. 29 - en hoe kon dit, in die lig van Hand. $11: 30$ ?); en dan die begrip ,ampsdraer" (p. 29, vgl. my art. in In die Skriflig, jrg. 10, nr. 37, p. 41 e.v.).

Ek moet my kollega versigtig verdink dat hy sterk struktureelbepaald gedink het, want dit gaan oor die „presbiteriaat” (p. 23), Kerkordelike reëlings van later tyd (d.w.s. strukturering) wat 'n "terugprojeksie" kon wees (p. 23); 'n ,institusionele" periode na die charismatiese; ,aanstelling van ouderlinge" wat dan 'n kollege (d.w.s. 'n struktuur) van sewe vorm (p. 26) wat enigsins met 'n „presbiterium" en 'n joodse ,instituut" vergelyk kan word. Hierdie strukture is m.i. heeltemal sekondêr en kan niks m.b.t. die instelling bewys nie. Die Skrif vermeld immers nergens die instelling van ' $n$ struktuur soos presbiterium of kerkraad of sinode nie. Dit vermeld slegs in die meervoud die instelling en aanstelling van manne, mense, dienaars as bedienaar, apostels, ouderlinge, ens.

Hiermee wil ek nie ontken dat derglike manne ook saamgekom (of as u wil „vergader" mits u nie summier die struktuur „vergadering" daarby verstaan nie) het nie. Hand. 15 is daarvan immers 'n voorbeeld hoe apostels, ouderlinge en broeders (telkens meervoud) saamgekom het. Maar die punt is dit: daar is eers ouderlinge in die meervoud en hulle bevoegdheid strek veel wyer as die sake wat hulle ter vergadering (Hand. 15) bring. M.i. het ons hier met 'n kern kerkregtelike verskil tussen die presbiteriale en kollegialistiese stelsels te doen. Die vergadering in die presbiteriale stelsel is ' $n$ samekoms van ouderlinge (soos dit ook in ouer Kerkordes genoem was), 'n geleentheid, 'n gebeure en nie 'n struktuur nie. Die vergadering in die kollegialistiese stelsel is egter 'n primêre begrip, 'n struktuur wat lede het en wat homself aanvul en aan sy lede hulle opdragte en taak toewys. Bedoel Goppelt met sy ,soort leidinggewende kollege” (p. 25) nie so iets nie? M.a.w. in die kollegialistiese stelsel is die struktuur primêr. In die presbiteriale opvatting staan die diens, die werk en funksie van die ouderling voorop (vgl. art. 2 K.O.). In die kollegialistiese stelsel staan die struktuur van ,amp”, ,vergadering”, kerkraad, sinode voorop. Die waardigheid, posisie kragtens struktuur en aanstelling, die eer ens. weeg swaar, terwyl in die presbiteriale visie die roeping, die bediening, die diens voorop moet staan.

My beskeie mening is dus dat ons die verstaan van Hand. 6 net bemoeilik wanneer ons dit in die lig van latere strukturele ontwikkelinge rondom begrippe soos „presbiterium”, „amp" of wat ook al probeer doen.

4.2. Ek meen dat waar die strukture presbiterium of amp as sodanig nie in die N.T. omskryf word nie, ons ook moet oppas om gawe (charisma) en amp (wat dan ook daaronder verstaan word) teenoor mekaar te stel. Ek weet dat ook in die aanhalings hierbo Floor soms outoriteite aanhaal wat nie per se sy opinie verteenwoordig nie. Hy defineer ,amp" as „openlik-deur-die-gemeente-erkende-gawe" (p. 30) en wil amp en gawe versoen (p. 31). Of hy 
altyd konsekwent die een as die ander aan ons kan voorstel, is vir my nie so duidelik nie. Persoonlik hou ek van die woord diakonia of diens (bediening, funksie, werk, taak, roeping) in plaas van ,amp”. Ridderbos sê iewers in sy "Paulus" dat "charisma" die diakonia in die gemeente van God se kant en „diakonia” die charisma van die gemeente se kant beskryf. D.w.s. waar die gawe van regering in die gemeente werk, is dit diakonia - en die diakonia as bediening van die Woord en Gees is gawe in die gemeente. Daarom doen die definisie van amp as ,openlik-deur-die-gemeente-erkende-gawe" vir my nog te kort aan die vertikale dimensie, naamlik roeping van God en gawe van God in die gemeente. Die openlike erkenning daarvan deur die gemeente kan ons hoogstens op die ,bevestiging” betrek as 'n antwoord van die gemeente op wat God primêr met roeping doen.

5. Die gevaar van retrojeksie en invloed vanuit ons huidige strukturele opvattings skemer ook deur wanner Floor argumenteer dat hy die sewe nergens besig vind „om as diakens... op te tree nie" (p. 25). Laat Floor hom by die maak van hierdie stelling nie lei deur 'n bepaalde geykte opvatting oor die diaken-,,amp" nie? Is dit reeds uitgemaak presies wat diakendiens is? Indien nie, kan ' $n$ mens dan iets aflei uit die bedrywigheid van die sewe? Ek neem aan dat Floor die sewe met 'n vorm van ,barmhartigheidsdiens" besig wou vind - en probleme het omdat ons vandag nie 'n taak vir diakens m.b.t. Woordverkondiging ken nie. Floor het probleme omdat van die sewe as evangeliste (Hand. 8) bekendheid bereik het.

Ook hier dink ek ons moet primêr vra hoe het dit in die ou Chr. kerk gebeur en ons moet nie met huidige opvattings, strukture en instellings na die verlede teruggaan nie. 'n Historiese beeld moet immers altyd met die historiese metode en derhalwe krities daargestel word. Die vraag is: hoe was dit toe eintlik gewees? Ek wil dan maar net vra of woordverkondiging, sending, evangelisasie, onderrig cris. nie veel meer die ,amp" van elke gelowige was nie en dus ook deur elke gelowige wat diaken was volbring is nie (vgl. 1 Kor. $14: 26)$ - en behoort woordverkondiging en evangelisasie kwansuis vandag glad nie tot die taak van 'n diaken of 'n gelowige Christen nie? Is dit nie veel eerder 'n jammerlike gevolg van die institusionalisering in die Westerse kerk, die Roomse opvatting van 'n ecclessia docens teenoor die ecclessia audiens, ons aanleg vir strukture en kompartemente wat in baie opsigte die kerk (die gelowiges) onmondig en monddood vir die evangelie gemaak het nie en die uitdra van die woord suiwer in hande van ,ampsdraers" (en dan domnees, spesiale evangeliseerders, sendelinge en ,helpers" en katkisasie ,behulpsels") gelaat het nie? Kan ons en mag ons dan enigsins hierdie kriteria aanlê?

6. Persoonlik ken ek die menings van prof. Floor goed en verdink hom glad nie van instemming met Bornkamm se opvatting dat Lukas twee "modelle" tot een "model" gegiet het nie (p. 28). Tog meen ek dat hy sy kritiek hier verswyg het, waarskynlik omdat hy slegs Bornkamm wou weergee. Ek meen dat ons soos Bornkamm kan redeneer, maar dan redeneer ons soos die Lutherane en kollegialiste. Vir hulle kom die kerkorganisasie suiwer uit die behoefte van el- 
ke tyd op, volg die "model" van wêreldlike of kerklike regeringe wat hulle ken en kan van tyd tot tyd aangepas word aan moderne behoeftes. Hierdie opvatting het binne die Geref. Kerken van Nederland aanleiding gegee tot hulle totaal nuwe Kerkorde wat in wese 'n pragmatiese reglemente bundel en struktuur is. Die kerk maak dan uit in sinode hoe die regeringstruktuur moet wees en bepaal derhalwe wat die "amp" van ouderling of diaken of struktuur van vergadering inhou. Daarteenoor aanvaar ek dat in die Skrif beginsels van kerkregering gegee is en dat die ouderling met sy roeping tot regering as opsiener ' $n$ instelling van Christus is. Ek wil nie van "modelle" (L.W.: die strukturele) praat nie, maar van instelling van Christus praat. Ek meen dat ons die Duitse outeurs altyd krities moet lees teen die lig van hulle opvatting dat kerkorganisasie tot die sigbare kerk behoort, terwyl die eintlike kerk onsigbaar is omdat geloof die bepalende faktor is.

7. Samevatting. Ek stem volkome met Floor saam dat ons in Hand. 6 alle bewyse vind dat daar ' $n$ bepaalde kerklike diens ingestel en bevestig is. Dit is ook waar dat die diens nie die bepaalde naam van "diaken" ontvang het nie, maar inhoudelik gerig was op die bediening van die tafels. Dit is gevolglik ook 'n diens (amp) met ' $n$ ander of liewer wyer inhoud en konotasie as die reformatoriese diakenamp wat tot armversorging beperk is.

Ek verskil egter radikaal met die stelling dat hier in Hand. 6 'n ouderling ,amp" ingestel is, omdat die begrip ouderling wat Floor saam met Robberts as opsiener gekwalifiseer verstaan (p. 29), uitdruklik met die taak, funksie of diens saamval wat die apostels vir hulleself in Hand. $6: 2$ in onderskeiding met die ingestelde diens van Hand. $6: 3$ reserveer.

Ek aanvaar nie dat die N.T. so struktureel-bepaald was dat daar enige probleem bestaan het om die apostels saam met of selfs sonder ander verkose en bevestigde ouderlinge (soos Matthias, Barnabas, Silas, en baie ander) as ouderlinge te ken nie.

Die instelling van die dienste kan nie met formele en strukturele argumente uitgemaak word nie. Die bepalende vraag moet gerig wees op die inhoud van die dienste, die wat van hulle taak, die wat hulle moes doen. Ouderlinge moet opsien, herder wees, regeer. Die diens wat in Hand. 6 ingestel is, moes tafels versorg, stoflike gawes onder die gemeente uitdeel sodat die apostels (destyds in vergelykinge met die sinagoge „ouderlinge") met die geestelike werk, die bediening van die woord van God, ongehinderd kon aangaan. Die diens wat in Hand. 6 ingestel is, het langs die apostoliese opsienersdiens of ouderlingsdiens tot stand gekom en kan nie as 'n instelling van die „ouderlingsamp” beskou word nie. 